\title{
A Note on Non - Singular Rings
}

Nazar H. Shuker

Anas S.Youns

anass.youns@uomosul.edu.iq

College of Computer Sciences and Mathematics

University of Mosul, Iraq

\section{Received on: 29/03/2004}

\section{ABSTRACT}

Accepted on: 13/12/2004

In this paper several new properties of singular ideals and nonsingular rings are obtained, a connection between a singular ideal and the Jacobson radical is considered, and a sufficient condition for a nonsingular ring to be reduced is given.

Keywords: Singular Ideals, Duo Ring, Jacobson Radical

$$
\begin{aligned}
& \text { ملاحظة حول الحلقات غير المنفردة } \\
& \text { انس سالم يونس } \\
& \text { كلية علوم الحاسبات والرياضيات } \\
& \text { جامعة الدوصل } \\
& \text { تاريخ قبول البحث: 2004/12/13 } \\
& \text { تاريخ استلام البحث: 2004/03/29 } \\
& \text { الملخص } \\
& \text { في هذا البحث درسنا المثاليات المنفردة والحلقات غير المنفردة وأعطينا خواص جديدة لها }
\end{aligned}
$$

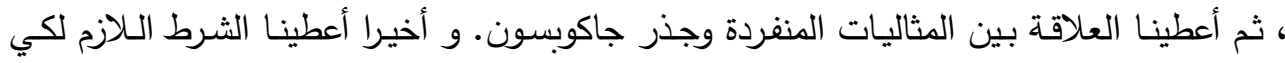

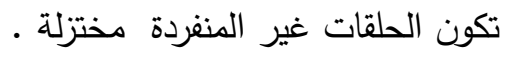

$$
\begin{aligned}
& \text { الكلمات المفتاحية : المثاليات المنفردة ، حلقة ديو ، جذرة المغرة جاكوبسون }
\end{aligned}
$$

\section{Introduction:}

Throughout this work all rings are assumed to be associative rings with identity. Recall that: 1 - A ring $R$ is said to be reduced if $R$ contains no non- zero nilpotent element ; 2 - A ring $\mathrm{R}$ is said to be a duo- ring if every right and left ideal is a two-sided ideal; 3- $J(R)$ and $\mathrm{N}$ will stand respectively for the Jacobson radical ideal of $\mathrm{R}$ and the set of all nilpotent elements; 4The right and left annihilators of a in $\mathrm{R}$ will be denoted by $\mathrm{r}(\mathrm{a})$ and $1(\mathrm{a})$, respectively ; 5- An ideal $I$ is said to be a right (left) pure if , for every $a \in I$, there exists $b \in I$ such that a=ab(ba).

\section{The Singular Ideals:}

In this section, new properties of singular ideals are given, and a connection between singular ideals and the Jacobson radical is obtained . 


\section{Definition 2.1:}

A non-zero elements a of $\mathrm{R}$ is said to be right singular if $\mathrm{r}(\mathrm{a})$ is an essential right ideal of $R$. The set of all right singular elements of $R$ is denoted by $\mathrm{Y}(\mathrm{R})$. The set of all left singular elements will be denoted by $\mathrm{Z}(\mathrm{R})$.

Clearly $\mathrm{Y}(\mathrm{R})$ and $\mathrm{Z}(\mathrm{R})$ are ideals of $\mathrm{R}$.

We shall begin this section with the following lemma .

\section{Lemma 2.2:}

If $a \in Y(R)$, then $r(1-a)=0$.

Proof: let a be a non- zero element in $\mathrm{Y}(\mathrm{R})$, then $\mathrm{r}(\mathrm{a})$ is a non-zero essential right ideal of $R$. Let $x \in r(a) \cap r(1-a)$, then a $. x=0$ and $(1-a) \cdot x=0$, this implies that $\mathrm{x}=0$ Therefore, $r(a) \cap r(1-a)=0$; since $r(a)$ is a non-zero essential right ideal of $R$, then $r(1-a)=0$.

Corollary 2.3: Let $R$ be a ring and $Y(R)=0$, the only idempotent element in $\mathrm{Y}(\mathrm{R})$ is zero .

Proof: Let $0 \neq a \in Y(R)$, and $a=a^{2}$, this implies that $a \cdot(1-a)=0$.

Hence $a \in r(1-a)$. By [Lemma 2.2.] ; $a=0$.

Next, we give the following result .

\section{Proposition 2.4:}

Let $\mathrm{R}$ be a ring with every right non-zero element is invertible, then $\mathrm{Y}(\mathrm{R}) \subseteq \mathrm{J}(\mathrm{R})$.

Proof: let $0 \neq \mathrm{a} \in \mathrm{Y}(\mathrm{R})$. Then by Lemma $2.2 \mathrm{r}(1-\mathrm{a})=0$, and hence 1 -a is invertable. Whence $a \in J(R)$.

Recall the following result of Ferreno and Puczylowski in [1].

\section{Lemma 2.5:}

Let $\mathrm{I}$ be a sem - prime ideal of $\mathrm{R}$, then :

$1-\mathrm{Y}(\mathrm{I})=\mathrm{I} \cap \mathrm{Y}(\mathrm{R})$.

$2-\mathrm{Z}(\mathrm{I})=\mathrm{I} \cap \quad \mathrm{Z}(\mathrm{R})$.

In view of the above lemma, we have the following :

\section{Proposition 2.6:}

Let I and $\mathrm{J}$ be semi - prime ideals of $\mathrm{R}$, then : 
If $\mathrm{I} \subseteq \mathrm{J}$, then $\mathrm{Y}(\mathrm{I}) \subseteq \mathrm{Y}(\mathrm{J})$.

If $\mathrm{I} \subseteq \mathrm{J}$, then $\mathrm{Z}(\mathrm{I}) \subseteq \mathrm{Z}(\mathrm{J})$.

Proof: Let $\mathrm{I} \subseteq \mathrm{J}$, and let $\mathrm{a} \in \mathrm{Y}(\mathrm{I})$, then by Lemma 2.5. $\mathrm{Y}(\mathrm{I})=\mathrm{I} \cap \mathrm{Y}(\mathrm{R})$, this implies that $a \in I$ and $a \in Y(R)$, and hence $a \in J$ and $Y(R)$.

Whence $\mathrm{a} \in \mathrm{J} \cap \mathrm{Y}(\mathrm{R})=\mathrm{Y}(\mathrm{J})$.

\section{Non - Singular Rings:}

This section is devoted to study non-singular rings, we give condition for non-singular rings to be reduced, and we characterize nonsingular rings in terms of maximal pure ideals and essential right ideals of R.

\section{Definition 3.1:}

A ring $R$ is said to be a right (left) non-singular if $Y(R)=0,(Z(R)=0)$. $A$ ring $R$ is said to be non - singular if $Y(R)=Z(R)=0$.

\section{Example:}

The ring of integers module $6, Z_{6}$ is a non-singular ring . Recall the following result of Ming in [2].

\section{Lemma 3.2:}

If $Y(R) \neq 0$, then there exists $y \in Y(R)$ such that $y^{2}=0$.

The following result characterizes non-singular rings in terms of maximal pure ideals .

\section{Theorem 3.3:}

Let $\mathrm{R}$ be a ring,such that for every nilpotent element $\mathrm{y}$ of $\mathrm{R}$, there exists a maximal pure right ideal $M$ such that $r(y) \subseteq M$. Then $R$ is a right non-singular ring.

Proof: Let $Y(R) \neq 0$, then by Lemma 3.2. , there exists a non-zero element $\mathrm{y}$ in $\mathrm{Y}(\mathrm{R})$ such that $\mathrm{y}^{2}=0$, then by the hypothesis there exists a maximal pure right ideal $M$ of $R$ such that $r(y) \subseteq M$. Since $\mathrm{y}^{2}=0$, then $\mathrm{y} \in \mathrm{r}(\mathrm{y}) \subseteq$ $M$, and since $M$ is a right pure, there exists $m \in M$ such that $y=y m$.

So, $\mathrm{y}(1-\mathrm{m})=0$. This implies that $1-\mathrm{m} \in \mathrm{r}(\mathrm{y}) \subseteq \mathrm{M}$, which means that $1 \in \mathrm{M}$, a contradiction. Therefore, $\mathrm{Y}(\mathrm{R})=0$.

Next, we give another condition for R to be a non-singular ring. 


\section{Proposition 3.4:}

Let $\mathrm{Y}(\mathrm{R})$ be a left pure ideal , then $\mathrm{R}$ is a right non - singular ring.

Proof: Let $Y(R)$ be a non- zero left pure ideal, and let a be a non - zero element in $Y(R)$, then there exists $b \in Y(R)$ such that $a=b a$. Since $b \in Y(R)$, then $r(b)$ is essential right ideal of $R$. We claim that $r(b) \cap a R=0$ .Let $x \in r(b) \bigcap a R$, then $b . x=0$ and $x=$ a.r for some $r \in R$, hence ba.r $=0$ . But $b a=a$, then we have a.r $=x=0$. Now, since $r(b)$ is an essential right ideal of $\mathrm{R}$, then $\mathrm{aR}=0$; and hence $\mathrm{a}=0$. Therefore $\mathrm{Y}(\mathrm{R})=0$.

It is well-known that if $\mathrm{R}$ is a reduced ring, then $\mathrm{R}$ is a non-singular ring. However, the converse is not true, as the following example shows:

\section{Example :}

Let $\mathrm{R}$ be the ring of $2 \mathrm{X} 2$ upper triangular matrices with entries in $\mathrm{Z}_{2}$, where $Z_{2}$ is the ring of integers modulo 2 , that is :

$\mathrm{R}=\left\{\left[\begin{array}{ll}a & b \\ 0 & c\end{array}\right]\right.$ where $\left.: \mathrm{a}, \mathrm{b}, \mathrm{c} \in \mathrm{Z}_{2}\right\}$.

Then by direct calculation, we observe that $\mathrm{R}$ is a non-singular ring but it is not reduced.

The following result gives a sufficient condition for non-singular rings to be reduced

\section{Theorem 3.5:}

Let $\mathrm{R}$ be a right non-singular ring with $\mathrm{l}(\mathrm{a}) \subseteq \mathrm{r}(\mathrm{a})$ for every $\mathrm{a} \in \mathrm{R}$. Then $\mathrm{R}$ is a reduced ring .

Proof: Let $a \in R$, and let $a^{2}=0$. We shall prove first that $r(a)$ is an essential right ideal of $\mathrm{R}$; if not , then there exists a right ideal $\mathrm{I}$ of $\mathrm{R}$ such that $r(a) \cap I=0$. Since $a \in 1(a)$, then $i . a \in 1(a)$ for all $i \in I$, which implies that $\mathrm{I} . \mathrm{a} \subseteq 1(\mathrm{a}) \subseteq \mathrm{r}(\mathrm{a})$. So I. $\mathrm{a} \subseteq \mathrm{I} \cap \mathrm{r}(\mathrm{a})=0$; this gives $\mathrm{I} . \mathrm{a}=0$, therefore I $\subseteq 1(\mathrm{a}) \subseteq \mathrm{r}(\mathrm{a})$, and hence $\mathrm{I}=0$. Therefore $\mathrm{r}(\mathrm{a})$ is an essential right ideal of $R$. This implies that $a \in Y(R)=0$. Thus $R$ is reduced.

Recall that an element a is said to be regular (in the sense of Von Neumann) if $\mathrm{a} \in \mathrm{aRa}$. 
Before closing this section, we present two additional results.

\section{Theorem 3.6:}

Let $\mathrm{R}$ be duo right singular ring, then any nilpotent element of $\mathrm{R}$ is regular.

Proof: Let $\mathrm{a} \in \mathrm{R}$, such that $\mathrm{a}^{\mathrm{n}}=0$ for some positive integer $\mathrm{n}$, and let $\mathrm{s}=\mathrm{a}^{\mathrm{n}-}$ $1 \neq 0$.

If $\mathrm{aR}$ is not an essential right ideal of $\mathrm{R}$, then there exists a nontrivial right ideal $\mathrm{K}$ of $\mathrm{R}$ such that $\mathrm{aR} \oplus \mathrm{K}$ is an essential right ideal of $\mathrm{R}$ .Suppose that a is not a regular element in $\mathrm{R}$, then $\mathrm{aR} \oplus \mathrm{K} \neq \mathrm{R}$.Observe that $\mathrm{sK} \subseteq \mathrm{K} \cap \mathrm{aR}=0$.

This implies that $\mathrm{K} \subseteq \mathrm{r}(\mathrm{s})$.

Now, since $\mathrm{a}^{\mathrm{n}}=0$, then $\mathrm{s} . \mathrm{a}=0$, hence $\mathrm{a} \in \mathrm{r}(\mathrm{s})$, this gives $\mathrm{aR} \subseteq$ $r(s)$.This means that $r(s)$ is an essential right ideal of $R$. Whence it follows that $s \in Y(R)=0$. This is a contradicition. Therefore, $a$ is a regular element of $\mathrm{R}$.

\section{Theorem 3.7:}

A ring $\mathrm{R}$ is right non-singular, if and only if $\mathrm{L}(\mathrm{I})=0$ for every essential right ideal $\mathrm{I}$ of $\mathrm{R}$.

Proof: Suppose that $R$ is a right non-singular ring, then $Y(R)=0$. Let $I$ be an essential right ideal of $\mathrm{R}$, such that $\mathrm{L}(\mathrm{I}) \neq 0$, then there exists a nonzero element $\mathrm{a}$ in $\mathrm{L}(\mathrm{I})$. This implies that $\mathrm{a} . \mathrm{I}=0$, and hence $\mathrm{I} \subseteq \mathrm{r}(\mathrm{a})$. Since $\mathrm{Y}(\mathrm{R})=0$, then $\mathrm{r}(\mathrm{a})$ is not essential right ideal of $\mathrm{R}$, and hence there exists a non- trivial right ideal $K$ of $R$, such that $r(a) \cap K=0$. Since $I \subseteq r(a)$ and $K . I \subseteq K \cap I$ then $\mathrm{K} . \mathrm{I} \subseteq \mathrm{K} \cap \mathrm{I} \subseteq \mathrm{K} \cap \mathrm{r}(\mathrm{a})=0$, which means that $\mathrm{K} \cap \mathrm{I}=0$, a contradiction.

Conversely, assume that $\mathrm{I}$ is an essential right ideal of $\mathrm{R}$, and let $\mathrm{L}(\mathrm{I})$ $=0$. Suppose that $\mathrm{Y}(\mathrm{R}) \neq 0$, and let a be a non - zero element in $\mathrm{Y}(\mathrm{R})$, then $r(a)$ is an essential right ideal of $R$. Since $L(I)=0$, then $L(r(a))=0$, then for every $\mathrm{y} \in \mathrm{r}(\mathrm{a})$, a.y. $=0$, hence $\mathrm{a} \in \mathrm{L}(\mathrm{y})=0$, a contradiction . Therefore $\mathrm{Y}(\mathrm{R})=0$. 


\section{$\underline{\text { REFERENCES }}$}

[1] Ferrero M. and E. Puczylowski, "The Singular Ideal and Radicals", J. Austral. Math. Soc. (series A), 1998 , pp. 195 - 209 .

[2] R.Y.C. Ming ; “On Quasi-injectivity and Von Neumann Regularity”,Monatshefle fur Math. 95 , (1983), pp.25- 32. 